\title{
ASSOCIATION OF VARICEAL BLEED WITH SEVERITY OF LIVER CIRRHOSIS AT A TERTIARY CARE HOSPITAL
}

\author{
DR. MUHAMMAD HASEEB ZIA, MBBS \\ NISHTAR HOSPITAL, MULTAN, PAKISTAN. \\ DR. HAMID SARWAR, MBBS \\ NISHTAR HOSPITAL, MULTAN, PAKISTAN. \\ DR. MUHAMMAD TAYYAB ASGHAR, MBBS \\ NISHTAR HOSPITAL, MULTAN, PAKISTAN.
}

\begin{abstract}
;
Background; A major cause of cirrhosis-related morbidity and mortality is the development of variceal bleeding, a direct consequence of portal hypertension. Each episode of active variceal bleeding is associated with 30 percent mortality. This study was planned to determine frequency of variceal bleeding in patients with liver cirrhosis and frequency of in-hospital mortality of these patients in our population. Objective; To determine the frequency of variceal bleed in hospitalized patients with cirrhosis of liver and its outcome in terms of in-hospital mortality. Material and Methods; Consecutive 139 Patient diagnosed with cirrhosis of liver were included in this cross-sectional study from department of Medicine, Bahawal Victoria hospital Bahawalpur. Complete history and physical examination was assessed to document duration of duration of liver disease, ascites, Hepatic encephalopathy, Previous GI bleed and systemic coagulopathy. All the patients had undergone diagnostic upper GI endoscopic examination to document varices. Results; Of these 139 study cases, 77 (55.4\%) were male and $62(44.6 \%)$ were female. Mean age of our study cases was $45.50 \pm 10.81$ years. Mean duration of disease (liver cirrhosis) was $3.25 \pm 2.32$ years. Majority of our study cases i.e. $94(67.6 \%)$ were having liver cirrhosis for the duration of less than 5 years. Child-Pugh class $C$ was more prevalent i.e. 77 (55.4\%) of our study cases. Variceal bleeding was observed in $100(71.9 \%)$ of our study cases. Frequency of mortality was $35(25.2 \%)$ in our study cases with liver cirrhosis, while frequency of mortality in patients with variceal bleeding was seen in $31(31 \%)$. Variceal bleeding was significantly associated with disease severity $(p<0.001)$. Conclusion; Very high frequency of variceal bleeding was observed in patients with liver cirrhosis. In-hospital mortality was significantly more prevalent in patients with variceal bleeding than without bleed. Variceal bleeding was significantly more seen in patients with increasing age, duration of disease and with more severe level of disease (Child Pugh class C). There was no statistically significant difference of bleeding with regards to gender.
\end{abstract}

Keywords; Liver Cirrhosis, Variceal bleeding, Mortality.

DOI: $10.7176 / \mathrm{JMPB} / 62-13$

Publication date: December $31^{\text {st }} 2019$

\section{Introduction;}

Cirrhosis of liver is one of the most frequently encountered entities in clinical setup all over the world especially in our subcontinent. It is defined as a process of diffuse fibrosis and loss of normal architecture with nodule formation ${ }^{1}$. Most common causes of this chronic hepatic condition are viral hepatitis, alcohol ${ }^{2}$ and metabolic causes like hemochromatosis and Wilson's disease. This alteration in hepatic architecture leads to hepatocyte damage and increased resistance to portal blood flow with increase in portal pressure known as portal hypertension. Portal hypertension is most important pathogenic mechanism for development of major complications o cirrhosis like ascites, variceal bleed, Hepatic encephalopathy and Hepatorenal syndrome ${ }^{3}$. Increased portal pressure causes opening up of portosystemic shunts on various sites in body, most important of which are at lower esophagus and stomach. These dilated blood vessels, called Esophageal and gastric varices, are most common cause of upper GIT bleeding in cirrhotic patients. About $65 \%$ cases of upper GI bleed (UGIB) in cirrhosis are due to esophageal varices ${ }^{4}$. Esophageal varices are present in $40 \%$ cases of cirrhosis at time of hospitalization ${ }^{5}$ and are present in $85 \%$ of child class $\mathrm{C}$ patients ${ }^{6}$. Variceal bleeding is second most common cause of death in patients with cirrhosis ${ }^{7}$. It carries a 6 week mortality of $10-20 \%{ }^{8}{ }^{10]}$ and 1 year mortality of $60 \%{ }^{9}$. Similar results were obtained by Hearnshaw and others who found mortality despite of modern methods of treatment to be $10 \%{ }^{11}$. 
Cirrhosis therefore is one of the most devastating illness affecting the world and particularly in our country. This study will help us to predict the prevalence of esophageal varices and its outcome in terms of in-hospital mortality.

\section{Material and Methods;}

Consecutive 139 Patient diagnosed with cirrhosis of liver irrespective of child Pugh class and duration of disease of either sex less than 70 years were included in this cross-sectional study from department of Medicine, Bahawal Victoria hospital Bahawalpur were included in the study. Patients admitted and expired due to causes other than cirrhosis of liver, acute liver failure, patients with upper GIT bleed with no varices or signs of portal hypertension on Endoscopy and with Coagulopathy were excluded. Informed consent was taken from each patient. Variceal bleed was defined by presence of: Clinical evidence of upper GI bleed in the form of hemetemesis and /or melena which is consistent with endoscopic evidence of esophageal and gastric varices. Complete history and physical examination was assessed to document duration of duration of liver disease, ascites, Hepatic encephalopathy, Previous GI bleed and systemic coagulopathy. All the patients had undergone diagnostic upper GI endoscopic examination to document varices. Data was entered and analyzed using computer program SPSS-16.

\section{Results;}

A total of 139 patients with liver cirrhosis meeting inclusion and exclusion criteria of this study were registered. Of these 139 study cases, $77(55.4 \%)$ were male and 62 (44.6\%) were female. Mean age of our study cases was $45.50 \pm 10.81$ years (minimum age was 19 years while maximum was 60 years). Study results have also indicated that majority of our cases were in the range of age groups 41 to 60 years i.e. 94 (67.62 \%). Mean duration of disease (liver cirrhosis) was $3.25 \pm 2.32$ years (minimum duration of disease was 1 year while maximum duration of disease was 9 years). Majority of our study cases i.e. 94 (67.6\%) were having liver cirrhosis for the duration of less than 5 years. Child-Pugh class $\mathrm{C}$ was more prevalent i.e. 77 (55.4\%) of our study cases. Variceal bleeding was observed in $100(71.9 \%)$ of our study cases. Frequency of mortality was 35 $(25.2 \%)$ in our study cases with liver cirrhosis while frequency of mortality in patients with variceal bleeding was seen in $31(31 \%)$ of patients i.e. 31/100. Frequencies of variceal bleeding in different child pugh classes has been described in Table No. 1.

Table-1

\section{Stratification of Variceal bleed with Severity of disease.}

$(n=139)$

\begin{tabular}{|c|c|c|c|}
\hline \multirow{2}{*}{ Disease Severity } & \multicolumn{2}{|c|}{ Variceal bleed } & \multirow{2}{*}{ P-Value } \\
\cline { 2 - 3 } & Yes $(\mathrm{n}=100)$ & $19(61 \%)$ & \\
\hline Child Pugh Class A & $12(39 \%)$ & & \\
\hline Child Pugh Class B & $15(48.3 \%)$ & $16(51.7 \%)$ & \\
(n=31) & & \\
\hline Child Pugh Class C \\
(n=77)
\end{tabular}




\section{Discussion;}

Cirrhosis affects 3.6 out of every 1000 adults in North America, and is responsible for over one million days of work loss and 32,000 deaths annually. A major cause of cirrhosis-related morbidity and mortality is the development of variceal bleeding, a direct consequence of portal hypertension ${ }^{12}$. Each episode of active variceal bleeding is associated with 30 percent mortality ${ }^{13}, 14$. In addition, survivors of an episode of active bleeding have a 70 percent risk of recurrent hemorrhage within one year of the bleeding episode ${ }^{15}$. Variceal bleeding occurs in 25 to 40 percent of patients with cirrhosis ${ }^{16}$. Our study registered 139 study cases, $77(55.4 \%)$ were male and $62(44.6 \%)$ were female patients having liver cirrhosis. Different authors have reported liver cirrhosis being more common among males than those of females. A study conducted by Sohail et al ${ }^{17}$ reported $56.7 \%$ male patients of cirrhosis in their study and $43.3 \%$ among females, our study results are close to that of Sohail et al ${ }^{17}$. Devrajani et $\mathrm{al}^{18}$ reported $59.3 \%$ male patients with liver cirrhosis and $40.7 \%$ female patients which are close to our stuedy results. Two other studies very high frequencies of male patients than females. ${ }^{19,20}$ Mean age of our study cases was $45.50 \pm 10.81$ years (minimum age was 19 years while maximum was 60 years). Study results have also indicated that majority of our cases were in the range of age groups 41 to 60 years i.e. 94 (67.62\%). Sohail et al ${ }^{17}$ reported $46 \pm 14$ years age of patients having cirrhosis, these findings are close to that of our study results. Sarwar et al reported mean age of cirrhotic patients as $52.57 \pm 11.39$ years, which is slightly higher than our results. ${ }^{19}$ Another study reported 50 years mean age of these patients, which is slightly higher than ours. ${ }^{20}$

Child-Pugh class C was more prevalent i.e. 77 (55.4\%) of our study cases. Similar findings have been observed by Kirge et $\mathrm{al}^{20}$. Variceal bleeding was observed in $100(71.9 \%)$ of our study cases. Variceal bleeding was significantly associated with that of severity of disease. Similar findings have been reported by Kirge et al ${ }^{20}$ who also reported variceal bleeding significantly more prevalent among patients with Child-Pugh class C. In our study, overall frequency of mortality was $35(25.2 \%)$ in our study cases with liver cirrhosis. Kirge et $\mathrm{al}^{20}$ reported $20.8 \%$ rate of mortality among cirrhotic patients, these findings are close to that of our study results. Pichilinque et al ${ }^{21}$ reported $18.03 \%$ in hospital mortality in patients having liver cirrhosis. Hearnshaw et al ${ }^{11}$ reported 10\% in-hospital mortality in patients having liver cirrhosis, this frequency is lesser than our study results. Sarwar et al ${ }^{19}$ reported $6.7 \%$ in-hospital mortality among Cirrhotic patients, which is quite less than our study results.

Variceal bleeding is associated with 30 percent mortality rates ${ }^{13,14}$ and our study results are also in accordance of these figures as frequency of mortality in patients with variceal bleeding was seen in 31 (31\%).In our study variceal bleeding was not significantly related to gender but was significantly more common with increasing age, duration of disease and Child pugh class $\mathrm{C}$ (severity of disease).

\section{Conclusion;}

Very high frequency of variceal bleeding was observed in patients with liver cirrhosis. In-hospital mortality was significantly more prevalent in patients with variceal bleeding than without bleed. Variceal bleeding was significantly more seen in patients with increasing age, duration of disease and with more severe level of disease (Child Pugh class C). There was no statistically significant difference of bleeding with regards to gender.

\section{References;}

1. Abul KA, Nelson F, John CA, Vinay K ,"Robbins' basic pathology", $8^{\text {th }}$ ed. New Dehli India:W B Saunders; 2010.P.837-38.

2. Adfd Nicki RC, Brian RW, Stuart HR, “Davidson's principles and practice of medicine” $21^{\text {st }}$ ed.New Dehli India: Elsevier; 2010. P.941-42

3. Bosch J, García-Pagán JC. Complications of cirrhosis. I. Portal hypertension. J Hepatol 2000;32:141-56

4. D’Amico G, Garcia Tsao G, Cales P.Diagnosis of portal hypertension. How and when. In: DeFranchis R,Editor. Portal hypertension III. Oxford:Blackwell Science Ltd:2001.36-64

5. Bosch J, Abraldes JG, Groszmann R. Current management of portal hypertension. J Hepatol 2003; 38 Supp11:54-68. 
6. Dite P, Micheal F, Labrecque D.World Gastroentology Prganisation (WGO). Esophageal Varices. Munich (Germany): World Gastroentology Prganisation (WGO);2008 jun.p.17.

7. Calès P, Pascal JP. Natural history of esophageal varices in cirrhosis (from origin to rupture). Gastroenterol Clin Biol,1988;12:245-54.

8. Dell'Era A, deFrancis R, Iannuzzi F. Acute variceal bleeding: pharmacological treatment and primary/secondary prophylaxis. Best Pract. Res Clin Gastroenterol 2008;22:279-94.

9. Sharara AI, Rockey DC. Gastroesophageal variceal hemorrhage. N Engl J Med 2001;345:669-81.

10. Illanueva C, Piqueras M, Aracil C. A randomized controlled trial comparing ligation and sclerotherapy as emergency endoscopic treatment added to somatostatin in acute variceal bleeding. J Hepato 2006;45:560-7.

11. Hearnshaw SA, Logan RF, Lowe D, Travis SP, Murphy MF, Palmer KR. Acute upper gastrointestinal bleeding in the UK: Patient characteristics, diagnoses and outcomes in the 2007 UK audit. Gut 2011;60(10):1327-35.

12. Garcia-Tsao G, Bosch J. Management of varices and variceal hemorrhage in cirrhosis. N Engl J Med 2010;362:823-32.

13. Smith JL, Graham DY. Variceal hemorrhage: a critical evaluation of survival analysis. Gastroenterology 1982;82:968-73.

14. DeDombal FT, Clarke JR, Clamp SE, Malizia G, Kotwal MR, Morgan AG. Prognostic factors in upper GI bleeding. Endoscopy 1986;18:6-10.

15. Graham DY, Smith JL. The course of patients after variceal hemorrhage. Gastroenterology 1981;80:800-9.

16. Grace ND. Prevention of initial variceal hemorrhage. Gastroenterol Clin North Am 1992;21:149-61.

17. Sohail AS, Mubashir A, Muhammad GH. Coagulation abnormalities in patients with chronic liver disease in Pakistan. J Pak Med Assoc 2011;61:364-65.

18. Devrajani BR, Talpur MAA, Rehman AA, Shah SZA, Das T, Devrajani T. Coagulopathies in patients with liver cirrhosis. World Appl Sci J. 2012;17(1):01-04.

19. Sarwar S, Dilshad A, Khan AA, Alam A, Butt AK, Tariq S, et al. J Coll Physicians Surg Pak. 2007;17(5):253-6.

20. Krige JEJ, Kotze UK, Sayed R, Burmeister S, Brnon M, Chinnery G. Outcome in decompensated alcoholic cirrhotic patients with acute variceal bleeding. S Afr Med J 2012;102(6):554-7.

21. Pichilingue Reto C, Queirolo Rodriguez FS, Ruiz Llenque JJ, Bravo Paredes E, Guzmán Rojas $\mathrm{P}$, Gallegos López R, et al. Frequency and mortality by rebleeding in cirrhotic patients treated for bleeding esophagic varices in two hospitals in Lima Peru during years 2009 to 2011. Rev Gastroenterol Peru. 2013;33(3):231-5. 